18

\title{
Анизотропия и спектроскопические свойства комплексов молекул мезо-тетра(4-карбоксифенил)порфирина с алмазными наночастицами
}

\author{
(C) Ю.А. Кальвинковская ${ }^{1 *}$, Ю.Б. Цаплев ${ }^{2}$, А.В. Трофимов ${ }^{2,3}$, А.А. Романенко ${ }^{1}$, \\ С.Б. Бушук ${ }^{4}$, Т.А. Павич ${ }^{1}$, В.А. Лапина ${ }^{1}$ \\ ${ }^{1}$ Институт фризики им. Б.И. Степанова НАН Беларуси, \\ 220072 Минск, Беларусь \\ ${ }^{2}$ Институт биохимической физики им. Н.М. Эмануэля РАН, \\ 119334 Москва, Россия \\ ${ }^{3}$ Московский фризико-технический институт (национальный исследовательский университет), \\ 141701 Долгопрудный, Московская обл., Россия \\ ${ }^{4}$ ГНПО „Оптика, оптоэлектроника и лазерная техника“, \\ 220072 Минск, Беларусь \\ * e-mail: juliet@ifanbel.bas-net.by
}

Поступила в редакцию 23.01.2020 г.

В окончательной редакции 23.01.2020 г.

Принята к публикации 15.03.2020 г.

\begin{abstract}
Спектроскопически исследованы комплексы мезо-тетра(4-карбоксифенил)порфирина с наноразмерными алмазами. Поляризационные характеристики их стационарной флуоресценции свидетельствуют об образовании ковалентно связанного комплекса между молекулами порфирина и алмазными наночастицами. На основе данных по стационарной анизотропии флуоресценции были оценены гидродинамические объемы исследованных комплексов. Проведенные измерения показали, что фотофизические свойства порфирина существенно не изменяются при образовании органо-неорганического гибридного комплекса с наноалмазами. Изученные комплексы могут быть перспективными в области биомедицинских исследований, в частности, в целях диагностики и разработки нового поколения фотосенсибилизаторов для практической медицины.
\end{abstract}

Ключевые слова: наноразмерные алмазы, мезо-тетра(4-карбоксифенил)порфирин, спектральнолюминесцентные свойства, стационарная анизотропия флуоресценции, фотосенсибилизаторы.

DOI: $10.21883 /$ OS.2020.09.49877.13-20

\section{Введение}

Порфирины являются важным классом пигментов, изучение фотофизических свойств которых представляет огромный интерес, так как они определяют их биологическую активность и использование в практической медицине. Известно, что порфирины могут использоваться как активные фотоагенты в различных оптических технологиях, в частности, в качестве фотосенсибилизаторов для целей фотодинамической терапии (ФДТ). В этой связи особое внимание привлекают порфирины с гидрофильными боковыми группами, так как они имеют высокую растворимость в водных растворах $[1,2]$. Однако молекулы порфиринов благодаря наличию заряженных групп в зависимости от окружения способны к различным реакциям агрегации, образованию димеров, олигомеров и т.д. [3], что существенно влияет на их фотофизические и функциональные свойства [4,5]. В настоящий момент проводятся многочисленные исследования по поиску носителей для молекул порфиринов, которые позволяют модулировать их свойства $[6,7]$, в частности, препятствовать обширной агрегации и сохранять свойства, присущие их мономерной форме. Одними из таких носителей являются наноалмазные частицы, так как они могут быть эффективно модифицированы благодаря наличию развитой химии поверхности [8] и могут образовывать гибридные органо-неорганические комплексы $[9,10]$.

В настоящей работе спектроскопическими методами исследован процесс формирования и свойства органонеорганического гибридного комплекса мезо-тетра(4карбоксифенил)порфирина с наноразмерными алмазами. Изучение фотофизических характеристик молекул порфирина в составе комплекса даст возможность тонкой настройки свойств комплекса для целенаправленного формирования эффективного фотодинамического агента и его дальнейшего использования.

\section{Экспериментальная часть}

\section{Приготовление образцов}

Для синтеза органо-неорганического гибридного комплекса мезо-тетра(4-карбоксифенил)порфирина с наноалмазами (ND-TCPP) и спектральных измерений использовали тетракарбоксифенилпорфирин (ТСРP) фирмы „PorphyChem“ (Франция), наноалмазы (ND) от 


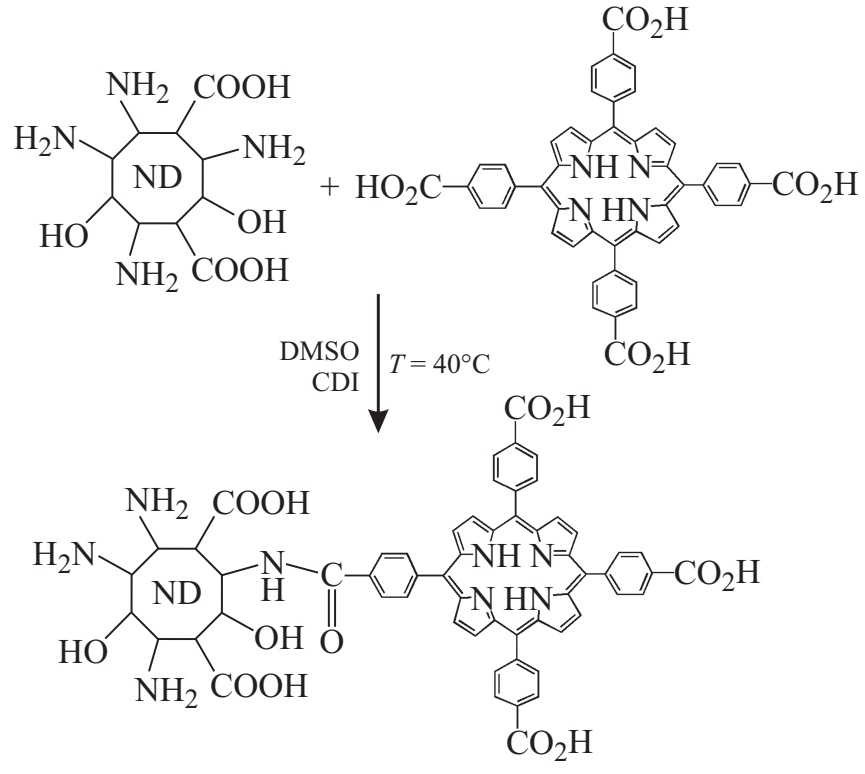

Рис. 1. Схема синтеза комплекса ND-TCPP.

производителя НП ЗАО „Синта“ (Минск, Республика Беларусь), 1, 1'-карбонилдиимидазол (CDI) и диметилсульфоксид (DMSO) производства фирмы „SigmaAldrich“, диэтиловый эфир, ацетон и глицерин - марки (х. ч.). Синтез комплекса ND-TCPP осуществляли согласно схеме, приведенной на рис. 1 , следующим образом: к раствору ТCPP в безводном DMSO добавляли 1, 1'-карбонилдиимидазол и перемешивали на магнитной мешалке в атмосфере азота. В полученную реакционную смесь приливали коллоидную суспензию ND при перемешивании на магнитной мешалке. Полученный таким образом комплекс ND-TCPP (рис. 1) очищали от свободного (избыточного) ТСРР и побочных продуктов реакции промывкой DMSO с дальнейшим центрифугированием.

Для записи спектров поляризации по возбуждению и испусканию были приготовлены растворы свободного основания ТCPР и комплекса ND-TCPP в маловязком растворителе ацетоне и в вязком растворителе глицерине при $T=293 \mathrm{~K}$ (вязкость ацетона $0.0003 \mathrm{~Pa} \cdot \mathrm{s}$, вязкость глицерина $0.9340 \mathrm{~Pa} \cdot \mathrm{s})$. Спектры возбуждения флуоресценции измеряли в фосфатном буфере ( $\mathrm{pH} 7.4)$ с добавлением 5\% DMSO. Все растворы имели одинаковую оптическую плотность 0.15 в максимуме поглощения полосы Соре ТСРP.

\section{Спектральные измерения}

Измерения стационарных спектров флуоресценции, возбуждения флуоресценции, спектральной зависимости анизотропии флуоресценции, а также кинетики затухания флуоресценции проводились с использованием многофункционального спектрофлуориметра Fluorolog-3 (Horiba Scientific, США-Франция-Япония). В стационарных измерениях в качестве источника возбуждения флуоресценции выступала непрерывная ксеноновая лампа мощностью $450 \mathrm{~W}$, излучение которой пропускалось через двойной монохроматор для выделения нужной длины волны возбуждения.

Все спектральные измерения проводились в стандартной 90-градусной геометрии, при комнатной температуpe. В канале регистрации флуоресценции использовался дифракционный спектрометр iHR320 (Horiba Scientific) и термоэлектрически охлаждаемый ФЭУ PPD-850 (Horiba Scientific) в качестве детектора. Спектры флуоресценции и спектры возбуждения флуоресценции были скорректированы на спектральную чувствительность прибора.

При измерении спектров анизотропии по испусканию и возбуждению предварительно определялась спектральная зависимость фактора коррекции $G(\lambda)$ на различное пропускание монохроматором вертикально и горизонтально поляризованного излучения.

С известным $G(\lambda)$ спектр анизотропии испускания и возбуждения вычислялся по формуле [11]:

$$
r(\lambda)=\frac{\left[I_{V V}(\lambda)-G(\lambda) I_{V H}(\lambda)\right]}{\left[I_{V V}(\lambda)+2 G(\lambda) I_{V H}(\lambda)\right]},
$$

где $I_{V V}-$ регистрируемая интенсивность флуоресценции при вертикальной поляризации возбуждения и вертикальной поляризации регистрируемого сигнала, $I_{V H}-$ регистрируемая интенсивность флуоресценции при вертикальной поляризации возбуждения и горизонтальной поляризации регистрируемого сигнала.

Кинетики затухания флуоресценции регистрировались методом времякоррелированного счета одиночных фотонов. В качестве источника возбуждения флуоресценции использовался импульсный светодиод DeltaDiode DD310 (Horiba Scientific) с пиковой длиной волны $314 \mathrm{~nm}$ и длительностью импульса возбуждения $0.9 \mathrm{~ns}$. Затухание сигнала флуоресценции аппроксимировалось в программном обеспечении DAS6 (Horiba Scientific) двухэкспоненциальной зависимостью с использованием соотношения

$$
I_{f}=B+A_{1} \exp \left(-t / \tau_{1}\right)+A_{2} \exp \left(-t / \tau_{2}\right),
$$

где $I_{f}(t)-$ зависимость интенсивности флуоресценции от времени, $\tau_{1}$ и $\tau_{2}-$ постоянные времени затухания, $B, A_{1}$ и $A_{2}$ - экспериментальные константы.

Весовой вклад $f_{i}$-компоненты с постоянной времени $\tau_{i}$ оценивался в соответствии с формулой

$$
f_{i}=\frac{A_{i} \tau_{i}}{\sum_{j=1}^{2} A_{j} \tau_{j}} .
$$

Среднее время жизни возбужденного состояния $\tau_{0}$ для случая регистрации затухания свечения определялось как

$$
\tau_{0}=\frac{A_{1} \tau_{1}^{2}+A_{2} \tau_{2}^{2}}{A_{1} \tau_{1}+A_{2} \tau_{2}} .
$$

Аппроксимация проводилась с использованием метода наименьших квадратов, качество аппроксимации оценивалось по приведенному параметру $\chi^{2}$. 


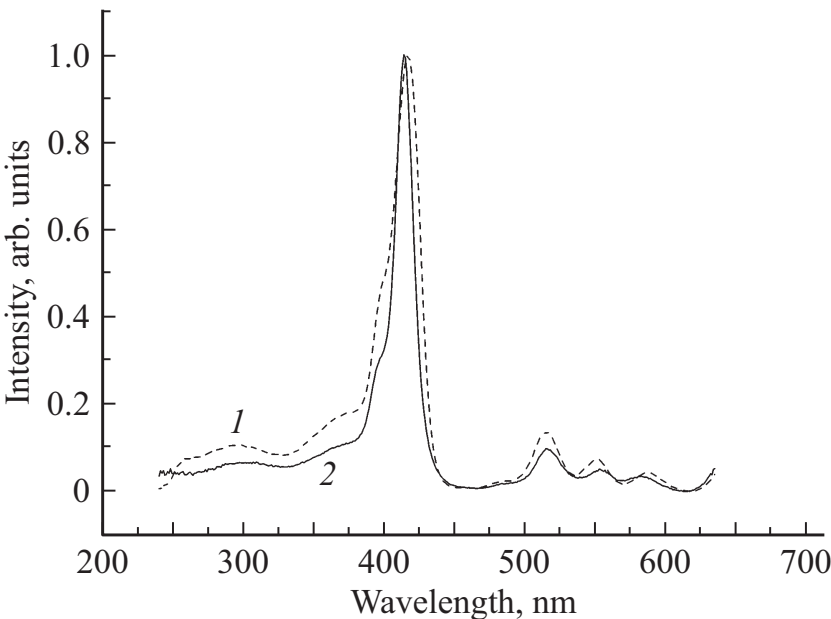

Pис. 2. Спектры возбуждения флуоресцении: 1 - ТСРР, 2 - ND-TCPP в фосфатном буфере (pH 7.4) с добавлением $5 \%$ DMSO. Длина волны регистрации $650 \mathrm{~nm}$.

\section{Результаты и их обсуждение}

На рис. 2 приведены спектры возбуждения флуоресценции свободного ТСРР и порфирина, включенного в нанокомплекс ND-TCPP, в фосфатном буфере (pH 7.4) с добавлением 5\% DMSO. Как видно, в спектрах наблюдаются характерные для порфиринов интенсивная полоса Соре в области $400 \mathrm{~nm}$ и обычно используемые для ФДТ $Q$-полосы поглощения в видимой области $450-650 \mathrm{~nm}$. По порядку интенсивности $Q$-полос ТСРР в данных условиях можно отнести к этио-типу [12]. Установлено небольшое смещение $Q$-полосы (в области $550 \mathrm{~nm}$ ) в длинноволновую область у связанного порфирина, что может косвенно свидетельствовать о наличии ковалентной связи порфирина с наночастицей.

Исследованы спектры флуоресценции свободного и включенного в нанокомплекс порфирина в буферных растворах (рис. 3). Спектры порфирина и нанокомплекса имеют две полосы испускания: полосу I (максимум $650 \mathrm{~nm}$ ) и полосу II (максимум $718 \mathrm{~nm}$ ). Спектр флуоресценции порфирина в составе нанокомплекса имеет незначительные отличия от спектра свободного порфирина. Таким образом, конъюгирование порфирина с наночастицами не оказывает существенного влияния на электронно-возбужденные уровни ТСРР, что является важным фактором для использования полученного нанокомплекса в качестве фотосенсибилизатора.

Время жизни флуоресценции свободного ТСРР и ND-TCPP было измерено в растворе в чистом диметилформамиде при длине волны регистрации $650 \mathrm{~nm}$. Параметры $\chi^{2}$ качества аппроксимации двухэкспоненциальной зависимостью для ТСРP и ND-TCPР составили соответственно 1.09 и 1.12. Времена затухания флуоресценции составили 11.2 и $3.1 \mathrm{~ns}$ с относительными вкладами 95 и 5\% для чистого ТСРР и 11.0 и $1.1 \mathrm{~ns}$ с относительными вкладами 87 и 13\% для ND-TCPP. Для раствора ND-TCPP наблюдалось уменьшение зна- чения короткого времени жизни и рост его вклада, что может быть соотнесено с образованием ковалентной связи молекулы порфирина с наноалмазом. Из ранее полученных спектральных данных для свободного порфирина и порфирина, включенного в нанокомплекс, было установлено, что коньюгирование порфирина с наночастицами не оказывает существенного влияния на фотофизические свойства ТСРР, что может объяснить малый вклад короткого времени жизни флуоресценции.

Средние времена жизни возбужденного состояния для свободного ТСРP $\left(\tau_{0}=10.8 \mathrm{~ns}\right)$ и для ND-TCPP $\left(\tau_{0}=9.8 \mathrm{~ns}\right)$ различаются незначительно.

\section{Анизотропия флуоресценции}

Поскольку вышеприведенные спектрально-люминесцентные исследования не могут дать однозначного свидетельства о наличии ковалентной связи между ТСРР и наноалмазной частицей в составе комплекса, были проведены исследования поляризационных характеристик (спектров анизотропии по возбуждению и испусканию) для свободного ТСРP и комплекса ND-TCPP в маловязком растворителе ацетоне и вязком растворителе глицерине. Можно предположить, что ковалентная связь молекулы ТСРР и наноалмазной частицы должна приводить к замедлению вращательной диффузии этой молекулы даже в маловязком ацетоне. Ожидаемые значения предельной стационарной анизотропии флуоресценции для молекулы ТСРР могут быть оценены по измерениям в глицерине. По данным [8], размер наноалмазной частицы составляет от 4 до $25 \mathrm{~nm}$, а молекулу ТСРР можно представить как плоскую молекулу [13], размер которой порядка $1.5 \mathrm{~nm}$.

По литературным данным [14], полосе Cope в поглощении и полосам испускания ТСРР может быть сопоставлена модель плоского осциллятора. По данным, приведенным в [12], при этом предельная анизотропия

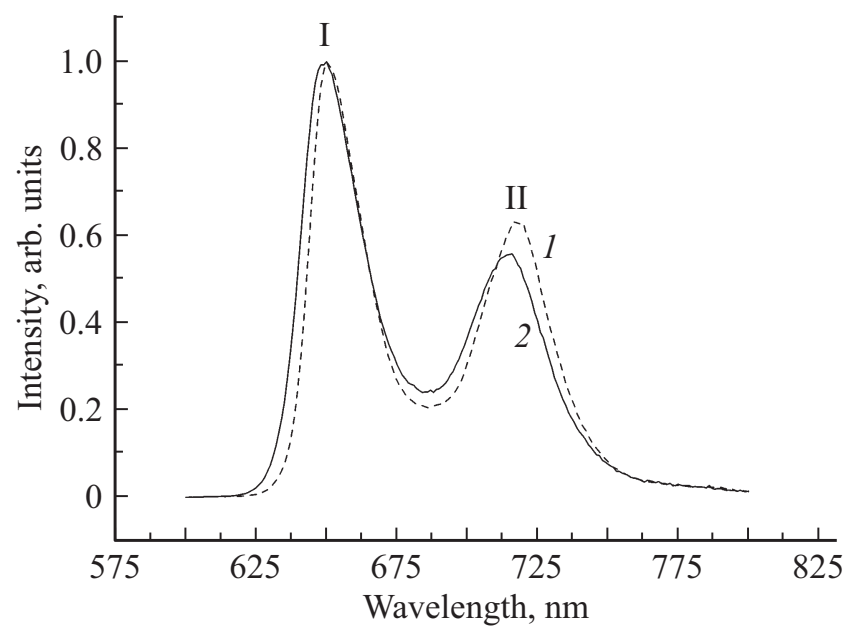

Рис. 3. Спектры флуоресцении: 1 - TCPP, $2-$ ND-TCPP в фосфатном буфере (pH 7.4) с добавлением 5\% DMSO. Длина волны возбуждения $420 \mathrm{~nm}$. 
по испусканию даже в отсутствие вращения молекул не превышает 0.1. Можно провести оценку ожидаемой степени анизотропии флуоресценции по формуле ЛевшинаПеррена:

$$
\frac{r_{0}}{r}=1+\frac{k_{B} T}{\eta V} \tau
$$

где $r$ - степень анизотропии в среде с вязкостью $\eta$, $r_{0}$ - предельная степень анизотропии, $k_{B}-$ постоянная Больцмана $\left(1.38 \cdot 10^{? 3} \mathrm{~J} / \mathrm{K}\right), V$ - объем молекулы с сольватной оболочкой, $T-$ температура, $\tau-$ время жизни возбужденного состояния. Формула (1) была получена в приближении сферической симметрии молекул. При $T=293 \mathrm{~K}$, вязкости ацетона $0.0003 \mathrm{~Pa} \cdot \mathrm{s}$ и вязкости глицерина0.9340 $\mathrm{Pa} \cdot \mathrm{s}, \tau \sim 11 \mathrm{~ns}$ и среднем диаметре наноалмаза $\sim 9 \mathrm{~nm}$ ожидаемые значения анизотропии для ТСРP и ND-TCPP в ацетоне составляют 0.003 и 0.070 соответственно, а в глицерине для ТСРР и ND-TCPP практически одинаковы $(\sim 0.090)$ и близки к предельной.

Были проведены измерения анизотропии флуоресценции TCPP и ND-TCPP по возбуждению и испусканию в ацетоне и глицерине. Измерения анизотропии по возбуждению проводились только в пределах полосы Cope. Спектры возбуждения флуоресценции ТСРР и ND-TCPP в области 375-450 nm в ацетоне и глицерине представлены на рис. 4.

Можно увидеть, что связывание ТСРР с наночастицей практически не оказывает влияние на положение спектров возбуждения флуоресценции в данном растворителе, однако влияние природы растворителя может быть зафиксировано по смещению спектров [15]. Небольшое красное смещение спектров возбуждения в глицерине можно объяснить большей полярностью глицерина по сравнению с ацетоном ( $\varepsilon=42.5$ для глицерина, $\varepsilon=20.7$ для ацетона). То же можно сказать и о спектрах флуоресценции, для которых влияние растворителя еще

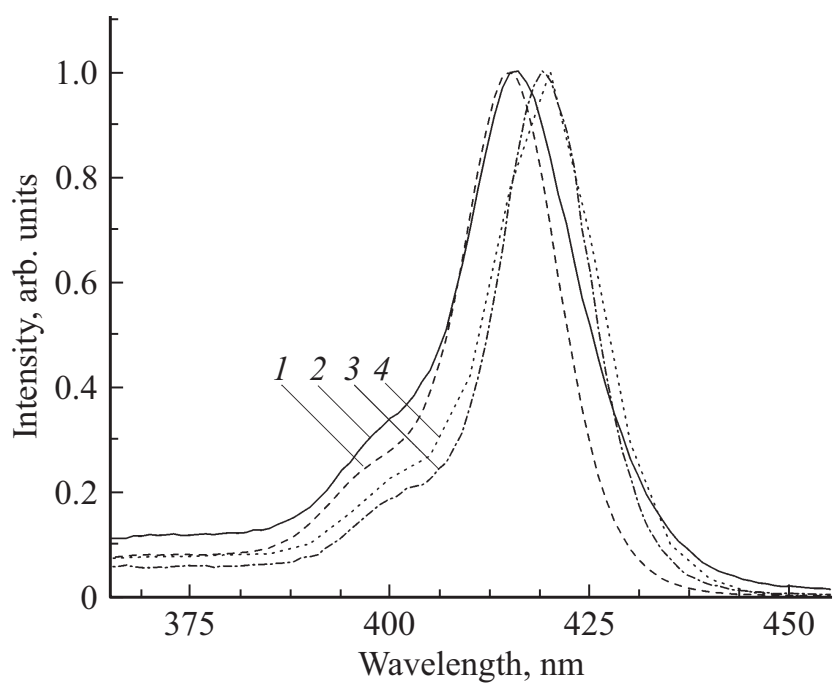

Рис. 4. Спектры возбуждения флуоресценции: 1 - ТСРР в ацетоне, $2-$ ND-TCPP в ацетоне, 3 - TCPP в глицерине, 4 - ND-TCPP в глицерине. Длина волны регистрации $650 \mathrm{~nm}$.

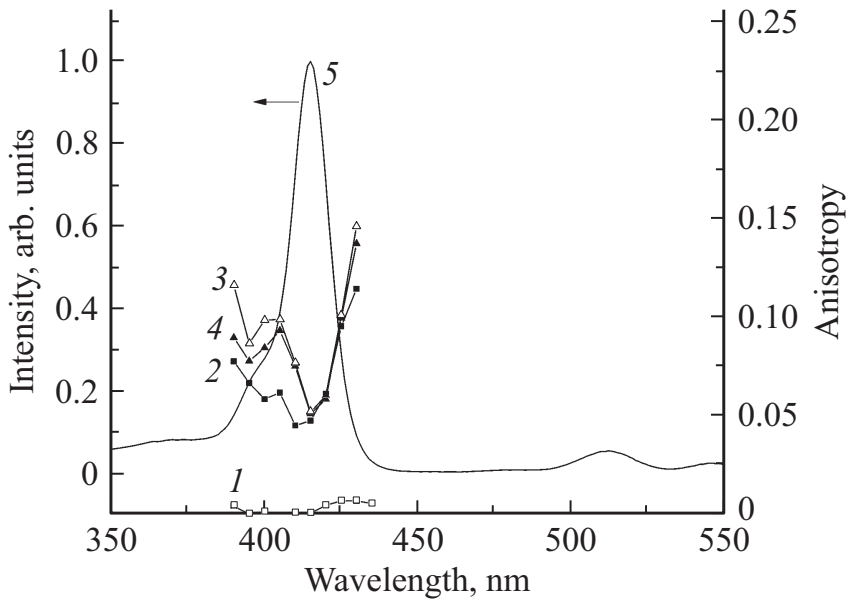

Pис. 5. Спектры анизотропии флуоресценции по возбуждению: 1 - TCPP в ацетоне, $2-$ ND-TCPP в ацетоне, $3-$ TCPP в глицерине, $4-$ ND-TCPР в глицерине, 5 - спектр возбуждения флуоресценции ТСРР в ацетоне. Длина волны регистрации флуоресценции $650 \mathrm{~nm}$.

менее заметно, поэтому в дальнейшем для иллюстрации будут приведены спектры возбуждения флуоресценции и флуоресценции ТСРР только для растворов в ацетоне.

Чтобы провести экспериментальную проверку вышеизложенных предположений, были проведены измерения спектров анизотропии флуоресценции ТCPP и ND-TCPP по возбуждению и испусканию, причем регистрация проводилась на длине волны $650 \mathrm{~nm}$, соответствующей максимуму полосы флуоресценции I (рис. 3). Как можно видеть на рис. 5, флуоресценция ТСРР в ацетоне практически полностью деполяризована, тогда как для ND-TCPP в ацетоне наблюдается среднее значение анизотропии около 0.1. Для случая растворов в глицерине анизотропия флуоресценции имеет близкие значения, причем даже для случая чистого ТСРР. Это можно объяснить заторможенностью вращения молекул ТСРР в более вязком растворителе.

Следует отметить существенную спектральную зависимость анизотропии по возбуждению. Ход кривых отчетливо выделяет две области в пределах полосы Cоре. Ранее в [16] было высказано предположение, подкрепленное расчетами и экспериментом, о том, что под контуром полосы Соре содержится два перехода, дипольные моменты переходов которых взаимно перпендикулярны. Спектры анизотропии по возбуждению при регистрации в максимуме полосы флуоресценции I при длине волны $650 \mathrm{~nm}$ показывают, что дипольный момент перехода, соответствующий этой полосе, имеет близкое направление с таковым для перехода в коротковолновой части полосы Cope, а переход в поглощении в длинноволновой части полосы Соре имеет дипольный момент перехода, находящийся под некоторым углом к таковому для этой же полосы флуоресценции.

Интересно отметить наличие второго минимума в спектрах анизотропии по возбуждению в районе $390 \mathrm{~nm}$ 


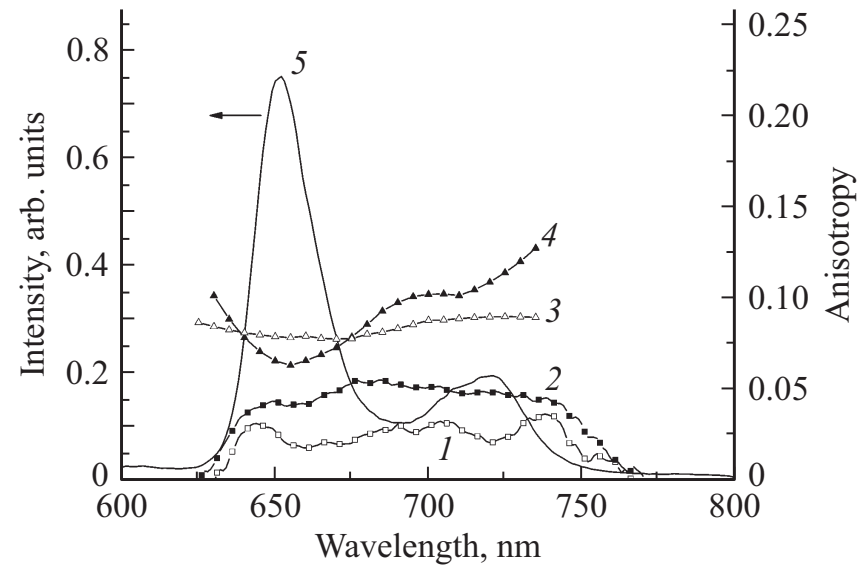

Рис. 6. Спектры анизотропии флуоресценции по испусканию: 1 - TCPP в ацетоне, 2 - ND-TCPP в ацетоне, 3 - TCPP в глицерине, 4 - ND-TCPP в глицерине, 5 - спектр флуоресценции ТСРР в ацетоне. Длина волны возбуждения $417 \mathrm{~nm}$.

(коротковолновое плечо полосы Соре), возможность которого была предсказана расчетно в работе [16].

На рис. 6 представлены спектры анизотропии ТСРР и ND-TCPP в ацетоне и глицерине по испусканию на фоне спектра флуоресценции ТСРР в ацетоне при длине волны возбуждения $417 \mathrm{~nm}$. Измерения спектров анизотропии флуоресценции по испусканию показали, в целом, соответствие приведенным выше ожидаемым значениям. Спектральная зависимость по спектру испускания при возбуждении в максимуме полосы Соpe $(417 \mathrm{~nm})$ практически отсутствует для растворов в ацетоне, слабо выражена для раствора ТСРР в глицерине, однако имеет хорошо выраженный вид для суспензии комплекса ND-TCPP в глицерине. На этой кривой имеется явный минимум в районе первой полосы флуоресценции (максимум $650 \mathrm{~nm}$ ), что можно ожидать, исходя из анализа спектральной зависимости анизотропии по возбуждению. Также можно заметить минимум, соответствующий второй полосе флуоресценции. Наличие таких двух минимумов в случае NDТСРР в глицерине дает возможность сделать предположение о частично анизотропной природе осциллятора испускания также для полосы флуоресценции II (максимум $717 \mathrm{~nm}$ ), причем этот эффект проявляется для комплекса ND-TCPP в глицерине, но не проявляется для его суспензии в ацетоне. Можно предположить, что наличие ковалентной связи с наноалмазной частицей в сочетании с полярным и способным к образованию водородной связи глицерином приводит к изменению симметрии молекулы ТСРР в этом случае.

Полученные численные значения для анизотропии флуоресценции по испусканию и возбуждению свидетельствуют об образовании ковалентно связанного комплекса ND-TCPP.

На основании полученных данных имеется возможность оценить средние объемы комплекса ND-TCPP и молекулы ТСРР с сольватной оболочкой для аце- тона с вязкостью $\eta=0.0003 \mathrm{~Pa} \cdot \mathrm{s}$ при $T=293 \mathrm{~K}$ и $\tau \sim 11 \mathrm{~ns}$, используя формулу Левшина-Перрена (1). Средние значения анизотропии в пределах первой полосы испускания $(650 \mathrm{~nm})$ для ND-TCPP и для TCPP составляют 0.06 и 0.02 соответственно. Тогда для средних гидродинамических объемов комплекса ND-TCPP и молекулы ТCPP получим $V_{\mathrm{ND}-\mathrm{TCPP}} \sim 220 \cdot 10^{-27} \mathrm{~m}^{3}$ и $V_{\text {ТсрР }} \sim 37 \cdot 10^{-27} \mathrm{~m}^{3}$. Из этих данных можно оценить средние диаметры комплекса и молекулы ТСРР в приближении сферической частицы: $D_{\mathrm{ND}-\mathrm{TCPP}} \sim 7.5 \cdot 10^{-9} \mathrm{~m}$ и $D_{\text {TсрР }} \sim 2.1 \cdot 10^{-9} \mathrm{~m}$. Данные, полученные для ТСРР, близки к реальным геометрическим размерам молекулы $1.5 \mathrm{~nm}$. Оцененный размер для комплекса оказался меньше среднего ожидаемого $(14 \mathrm{~nm})$. Такая заниженная оценка может быть связана с возможной свободой вращения молекулы ТСРР в составе комплекса вокруг ковалентной амидной связи.

\section{Заключение}

Проведенные спектроскопические исследования показали, что конъюгирование порфирина с наночастицами не оказывает существенного влияния на электронно-возбужденные уровни мезо-тетра(4-карбоксифенил)порфирина, что является важным фактором для использования полученного нанокомплекса в качестве фотосенсибилизатора. Наноалмазные частицы выступают как стабилизаторы для молекул порфиринов, в частности, препятствуют обширной агрегации порфиринов и способствуют сохранению свойств, присущих их мономерной форме. Анализ полученных спектральных данных свидетельствует о незначительном влиянии окружения, в частности растворителя, на фотофизические свойства ТСРР в составе комплекса.

Исследования спектров анизотропии флуоресценции TCPP и ND-TCPP по испусканию и возбуждению в ацетоне и глицерине показали, что флуоресценция ТСРP в ацетоне практически полностью деполяризована, тогда как для ND-TCPP в ацетоне наблюдается значение анизотропии флуоресценции в среднем около 0.1. Ковалентная связь молекулы ТСРР и наноалмазной частицы приводит к значительному замедлению вращательной диффузии этой молекулы даже в маловязком ацетоне. Для случая растворов в глицерине значение анизотропии флуоресценции имеет близкую величину, причем даже для случая чистого ТСРР. Из поляризационных характеристик по испусканию оценены средние диаметры комплекса ND-TCPP и молекулы TCPP в приближении сферической частицы. Оценочные величины для комплексов оказались систематически ниже их реальных размеров, что говорит о некоторой свободе движения молекул порфирина вокруг его ковалентной связи с наноалмазной частицей. Таким образом, проведенные исследования свидетельствуют об образовании ковалентно связанного органо-неорганического гибридного комплекса ND-TCPP. Изученные комплексы могут быть использованы в области биомедицинских исследований, 
направленных на создание нового поколения фотосенсибилизаторов для практической медицины.

Изучение фотофизических и медико-биологических свойств порфиринов и их комплексов продолжает оставаться актуальным в связи с уникальными возможностями их практического применения.

\section{Финансирование работы}

Работа выполнена при финансовой поддержке гранта БРФФИ (грант № Ф18Р-206) и РФФИ (грант № 18-5300038 Бел_а ).

\section{Конфликт интересов}

Авторы заявляют, что у них нет конфликта интересов.

\section{Список литературы}

[1] Hu Z., Pan Y., Wang J., Chen J., Li J., Ren L. // Biomed. Pharmacother. 2009. V. 63. N 2. P. 155.

[2] Chitgupi U., Lovell J., Rajendiran V. // Molecules. 2018. V. 23. N 4. P. 892. DOI: $10.3390 /$ molecules 23040892

[3] White W.I. // The Porphyrins / Ed. by Dolphin D. N. Y.: Academic Press. 1979. V. 5. P. 303.

[4] Rotomskis R., Augulis R., Snitka V., Valiokas R., Liedberg B. // J. Phys. Chem. B. 2004. V. 108. P. 2833.

[5] Schwab A.D., Smith D.E., Rich C.S., Young E.R., Smith W.F., de Paula J.C. // J. Phys. Chem. B. 2003. V. 107. N 41. P. 11339. DOI: $10.1021 / \mathrm{jp} 035569 \mathrm{~b}$

[6] Yue Z.L., Eccleston M.E., Slater N.K.H. // Biomaterials. 2005. V. 26. N 32. P. 6357. DOI: 10.1016/j.biomaterials.2005.03.035

[7] Marie E., Landfester K., Antonietti M. // Biomacromolecules. 2002. V. 3. N 3. P. 475. DOI: $10.1021 / \mathrm{bm} 015634 \mathrm{~s}$

[8] Lapina V.A., Akhremkova G.S., Gubarevich T.M. // Russ. J. Phys. Chem. A. 2010. V. 84. N 3. P. 267.

[9] Lapina V.A., Bushuk S.B., Pavich T.A., Vorobey A. V. // J. Appl. Spectrosc. 2016. V. 83. N 3. P. 344. DOI: 10.1007/s10812-0160292-3

[10] Lapina V.A., Pavich T.A., Pershukevich P.P. // Opt. Spectrosc. 2017. V. 122. N 2. P. 219.

[11] Lakowicz J.R. Principles of Fluorescence Spectroscopy. N. Y.: Springer Science + Business Media, 2006. 954 p.

[12] Гуринович Г.П., Севченко А.Н., Соловьев К.Н. Спектроскопия хлорофилла и родственных соединений. Минск: Наука и техника, 1968. 517 с.

[13] Березин В.Д., Ениколопян Н.С. Металлопорфирины. М.: Наука, 1988. $160 \mathrm{c}$.

[14] Саржевский А.М., Севченко А.Н. Анизотропия поглощения и испускания света молекулами. Минск: Изд. БГУ, 1971. $332 \mathrm{c}$.

[15] Harriman A., Hosie R.J. // J. Chem. Soc. Faraday Trans. II. 1981. V. 77. N 9. P. 1695.

[16] Shkirman S.F., Solov'ev K.N., Kachura T.F., Arabei S.A., Skakovskii E.D. // J. Appl. Spectrosc. 1999. V. 66. N 1. P. 68. 